\title{
Erratum to: Cyclin D1 cooperates with p21 to regulate TGF $\beta$-mediated breast cancer cell migration and tumor local invasion
}

\author{
Meiou Dai ${ }^{1}$, Amal A. Al-Odaini ${ }^{1,2}$, Nadège Fils-Aimé ${ }^{1}$, Manuel A. Villatoro', Jimin Guo ${ }^{1}$, Ani Arakelian ${ }^{3}$, \\ Shafaat A. Rabbani ${ }^{3}$, Suhad Ali $^{1}$ and Jean Jacques Lebrun ${ }^{1 *}$
}

\section{Erratum}

Main text: After publication of this work [1] an error was noticed in Fig. 5c. Figure 5c shows representative images/fields of PTGS2 staining of mammary tumors derived from mice injected with parental SCP2 cells versus mice injected with p21/cyclinD1 depleted SCP2 cells. Tissue slides from the two groups of animals were stained with an anti-PTGS2 antibody. Results showed a decrease in PTGS2 staining in the cyclinD1/p21 depleted group compared to the parental group.

The tumor images in Fig. $5 \mathrm{c}$ came from two different mice for each group and not 4 as mistakenly indicated. Two representative images were used for each mouse but were largely overlapping. Thus, to avoid confusion, we have removed the overlapping images and retained 1 representative image for each of the 4 mice (2 mice injected with parental SCP2 cells and 2 mice injected with $\mathrm{p} 21 /$ cyclinD1 depleted SCP2 cells). We apologize for this error, which did not affect any of the interpretations or conclusions of the article.

\begin{abstract}
Author details
'Division of Medical Oncology, Department of Medicine, McGill University Health Center, Royal Victoria Hospital, Montreal, QC, Canada. ${ }^{2}$ University of Dammam, Ministry of Higher Education, Riyadh, Saudi Arabia. ${ }^{3}$ Department of Medicine, McGill University Health Center, Royal Victoria Hospital, Montreal, QC, Canada.
\end{abstract}

Received: 6 March 2017 Accepted: 6 March 2017

Published online: 28 March 2017

\section{Reference}

1. Dai M, et al. Cyclin D1 cooperates with p21 to regulate TGFbeta-mediated

breast cancer cell migration and tumor local invasion. Breast Cancer Res. 2013;15(3):R49

\footnotetext{
* Correspondence: jj.lebrun@mcgill.ca

${ }^{1}$ Division of Medical Oncology, Department of Medicine, McGill University Health Center, Royal Victoria Hospital, Montreal, QC, Canada
} 


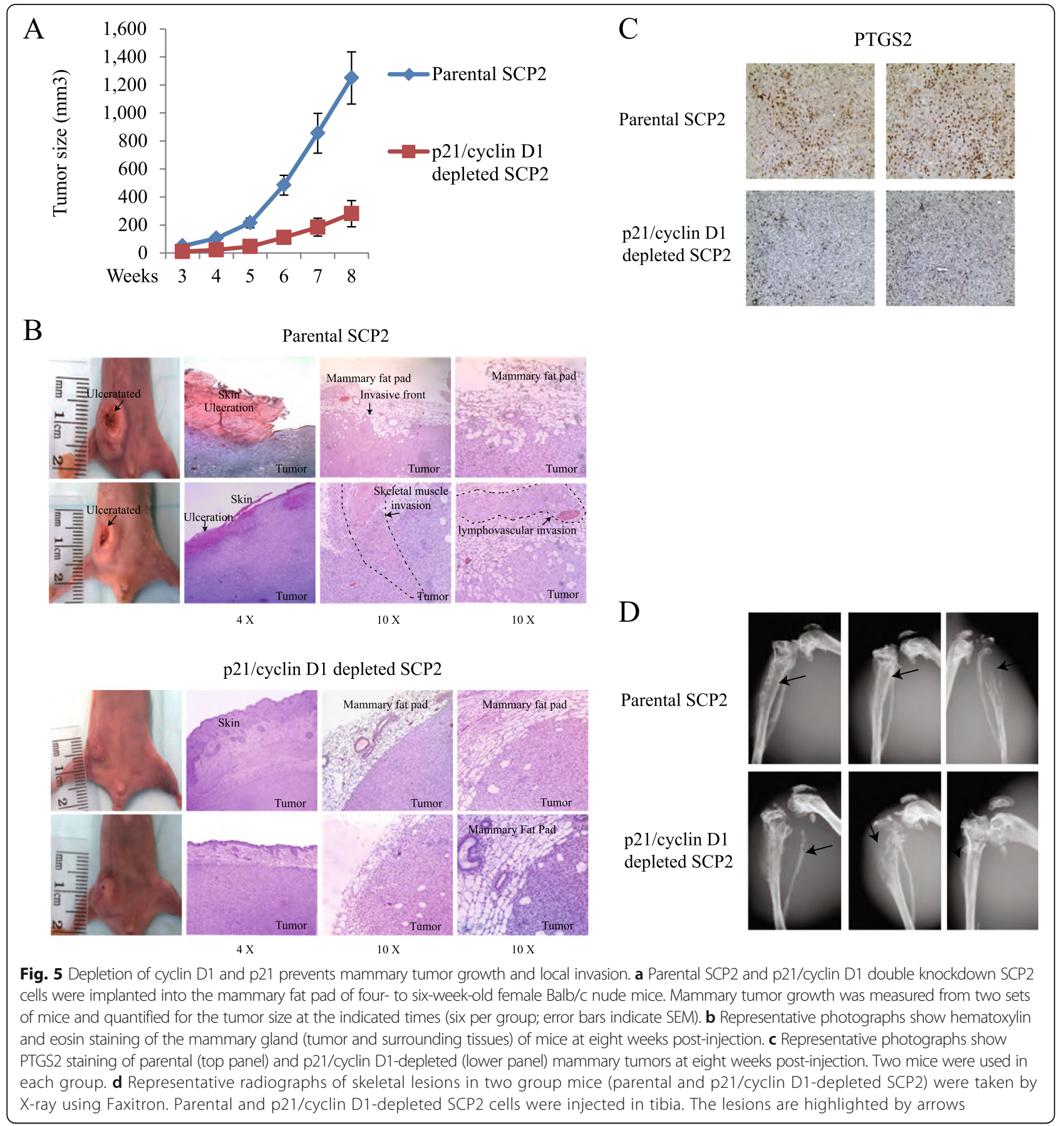

